\title{
THE IMPROVEMENT AND PERFORMANCE OF MOBILE ENVIRONMENT USING BOTH CLOUD AND TEXT COMPUTING
}

\author{
Dr.S.Saravana Kumar, J.Lakshmi Priya, P.Hannah Jennifer, \\ N.Jeff Monica and Fathima \\ Panimalar Institute of Information Technology Chennai, India \\ \{Saravanakumars81, hannahalbert0 7, lakshmibtch, monica.nedun, \\ ayeshu9298\}@gmail.com
}

\begin{abstract}
In this research paper presents an design model for file sharing system for ubiquitos mobile devices using both cloud and text computing. File sharing is one of the rationales for computer networks with increasing demand for file sharing applications and technologies in small and large enterprise networks and on the Internet. File transfer is an important process in any form of computing as we need to really share the data across. The Wireless Network changed the way we were sharing the files. Infra-Red and Bluetooth are the technology we use to share files in mobile phones and Bluetooth is the successful one. In exisiting system there is no immediate predecessor for the proposed system. Bluetooth file transfer is the already existing system. Drawbacks of Existing System are Short Range, Slow transfer rate and Unsecure. But in our research paper the idea is to use Both cloud and text computing network to transfer files.A wireless network is created and the devices connected in this network can share files between them. Benefits over the Existing System are more Secure, Range - upto 300 mts and Data rate is 50-140 mbps. In future without internet connection we can transfer our information very easily.Key words : cloud and text computing, Bluetooth, network, internet, system, file transfer.
\end{abstract}

\section{INTRODUCTION}

Cloud Computing and Text Computing are becoming the hottest topics due to the increase in the technological advancements. In this research wifi source is used instead of local network. You can shift your whole OS to the Web using the Concept of Cloud Computing. Text Computing is used as an addition feature to provide more performance measure and efficiency for Cloud Computing.

\section{WHAT IS CLOUD COMPUTING ?}

Cloud computing is Internet-based computing, whereby shared resources, software and information are provided to computers and other devices on-demand, like electricity. Computing in which services and storage are provided over the Internet (or "cloud").Cloud computing is a

Sundarapandian et al. (Eds) : ACITY, AIAA, CNSA, DPPR, NeCoM, WeST, DMS, P2PTM, VLSI - 2013

pp. 185-191, 2013. () CS \& IT-CSCP 2013

DOI : $10.5121 /$ csit.2013.3419 
general term for anything that involves delivering hosted services over the Internet. These services are broadly divided into three categories: Infrastructure-as-a-Service (IaaS), Platform-asa-Service (PaaS) and Software-as-a-Service (SaaS).

\subsection{Software as a Service}

With software as a service as large number of concern can access applications and large amounts of virtual computing power without buying it. instaed, the application is used by some other company, that huge loss of cost and time for the users. Some Service applications may operate via a connection between two or many networks. "Now we're talking about large number of computers" linked together via the Internet or some other network connection.

\section{PURPOSE OF CLOUd COMPUTING}

While using online storage application when it get stores or we going download else timing or any other internet-based application, you use Cloud and text Computing. Internet based applications is mainly used for daily in home, organization, schools, offices, social media, etc.

There are technological, economic and communications reasons for why Cloud Computing is used by many people. Simply we can one sentence, its user friendly, easier to learn and easy to understand by all people including new learner too, finally easy remember ever technical aspect.

\section{Advantages OF Cloud COMPUTING}

Main advantages of cloud computing Query Flooding and Query responses are monitored and kept on track for future verification in order to avoid major flaws in the system. Peer Nodes failure will be automatically updated to the fellow nodes and an automatic inherit plan occurs to avoid bifurcation of request to the failed peers.

\subsection{Reduced Cost:}

Cloud technology is paid incrementally, saving organizations money.

\subsection{Increased Storage:}

Organizations can store more data than on private computer systems.

\subsection{Highly Automated:}

No longer do IT personnel need to worry about keeping software up to date.

\subsection{Flexibility:}

Cloud computing offers much more flexibility than past computing methods. 


\subsection{More Mobility:}

Employees can access information wherever they are, rather than having to remain at their desks.

\subsection{Allows it to Focus:}

No longer having to worry about constant server updates and other computing issues, government organizations will be free to concentrate on innovation.

\section{REQUIREMENTS OF CLOUD COMPUTING}

Requirements specification is produced at the culmination of the analysis task. The function and performance allocated to software as part of system engineering are refined by establishing a complete information description as functional representation of system behavior, an indication of performance requirements and design constraints, appropriate validation criteria.

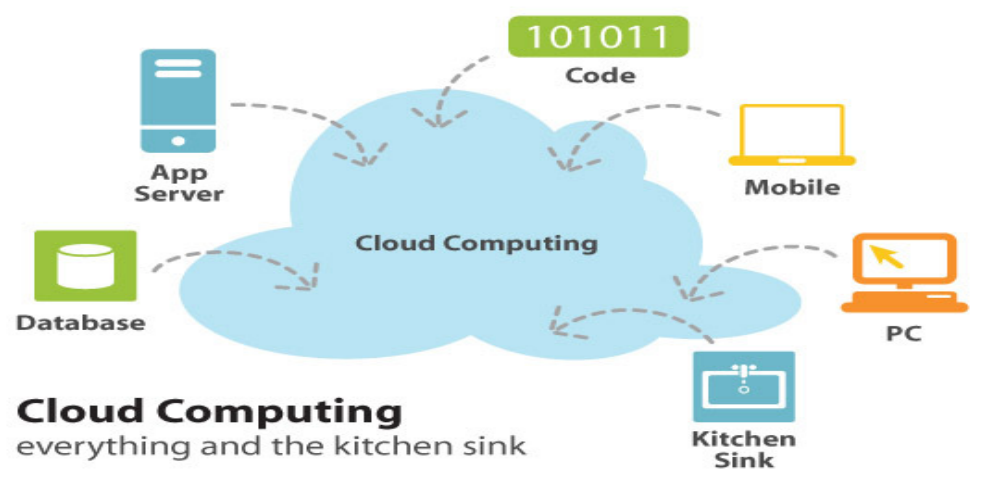

Figure 1.Cloud Computing Network

\section{Web OS- MEANS MOVING OS TO THE WEB}

This study is carried out to check the technical feasibility, that is, the technical requirements of the system. Any system developed must not have a high demand on the available technical resources. This will lead to high demands on the available technical resources. This will lead to high demands being placed on the client. The developed system must have a modest requirement, as only minimal or null changes are required for implementing this system.

Of course, the Web OS won't replace the traditional operating system any time soon. But as users become more comfortable working over the Web, the Web OS could become more popular. Nonetheless, the technology still has several important shortcomings that proponents must address.

\section{EARLY DEVELOPMENTS}

One of the Web OS's predecessors was Tarantella, which the Santa Cruz Operation launched in 1993. It was a Unix-based X Window System that worked over corporate networks and let PCs 
display a Unix desktop. However, the technology never caught on commercially. Sun acquired Tarantella in 2005 and integrated it into the SGD. In 1992, University of California, Berkeley, researchers began work on what, four years later, became Web OS. The system delivered OS like functionality via the Internet.

\section{INSIDE THE WEB OS}

Web OSs bring together Web based applications using the browser as the interface, which is designed to look like a traditional operating system's interface, as Figure 1 shows. They work with a URL-based file system that lets a Web based application access files from the OS provider's server online via a domain-name-system query. Similarly, the technology uses a location-independent resource naming system that lets applications make calls to services and resources on remote severs.

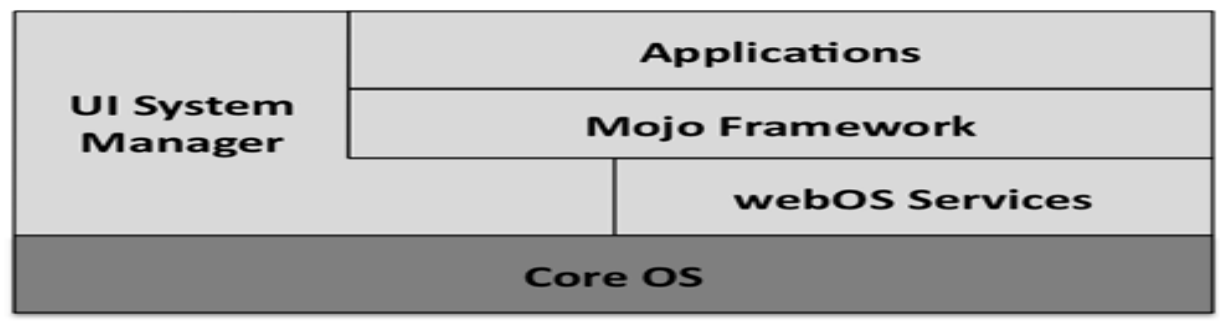

Figure 2. Simplified Web Os Architecture

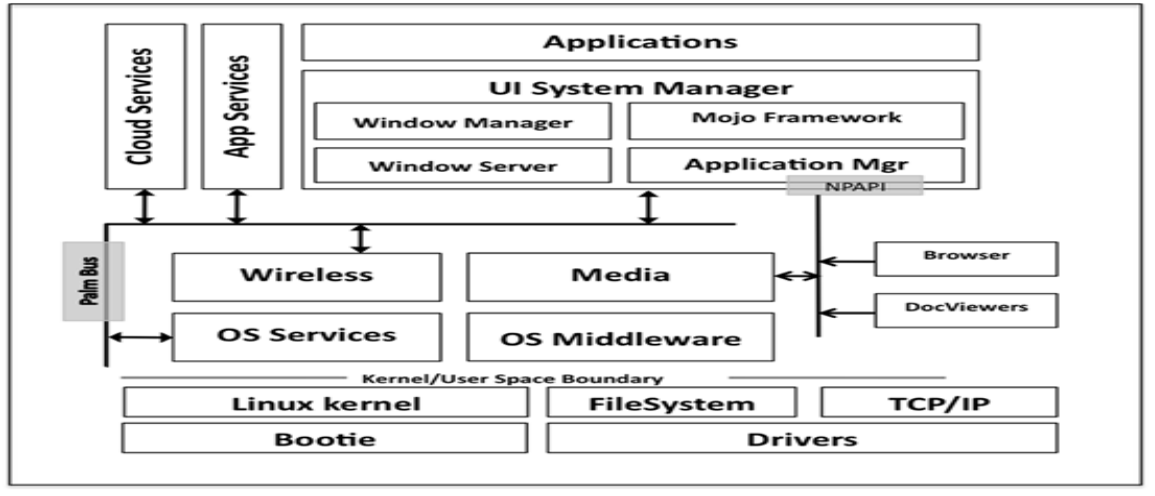

Figure 3. Web Os System Architecture

The Application Environment refers to Objector uses the term" agents" to represent some of the hardware and software systems. In Fusion method, there is no requirement phase, where a user will supply the initial requirement document. Any software project is worked out by both the analyst and the designer. The Architecture is a graphic tool used for expressing system requirements in a graphical form. The purpose of clarifying system requirements and identifying major transformations that to become program in system design. This can be stated as the starting point of the design phase that functionally decomposes the requirements specifications down to the lowest level of detail. It consist of series of bubbles joined by lines. The bubbles represent data transformations and the lines represent data flows in the system. This describes what that data flow in rather than how they are processed. So it does not depend on hardware, software, data structure or file organization. 


\section{ADVENT OF WEB APPLICATIONS}

The development of Web OSs has been the improvement of Web-based applications using text computing. Several of these applications have started gaining traction in recent years, particularly those for e-mail (such as Hotmail and Gmail), instant messaging, and storage (like Xdrive). Recently, there have also been Web -based word-processing and spreadsheet applications (such as Google Docs and Number). With the first generation of Web applications, implementing even some modest functions like dragging and dropping files, making minor changes to documents without having to refresh the entire page, and caching data locally-was difficult.

\section{TEXT COMPUTING}

Text computing is nothing but resources from multiple concern domains from a similar goal. Text Computing is an technology that provides seamless access to computing large amount of data storage capacity and distributed all over the world.

\subsection{Purpose of Text is Cloud}

The cloud computing is achieves its communication with supercomputing, or high-performance computing power, sequentially used by military and research facilities, to perform million of computations works per second, in consumer-oriented applications such as financial portfolios or even to deliver personalized information, or power immersive computer application likes multimedia, graphics ,etc . We can increase our ability of work it by coupling it with Text computing.

\subsection{The Text Batch System}

There are two fundamental data types in Text-Batch: table or indexed table (borrowed from database terminology). A table contains a set of records (rows) that are independent of each other. All records in a 730 table follow the same schema, and each record may contain several fields (columns). Indexed table is SIMILAR to table except that each record also has an associated index, where the index could simply be one of the fields or other data provided by the user. The Text-Batch system consists of two pieces of related software components: the distributed file system (DFS) and the job scheduler.

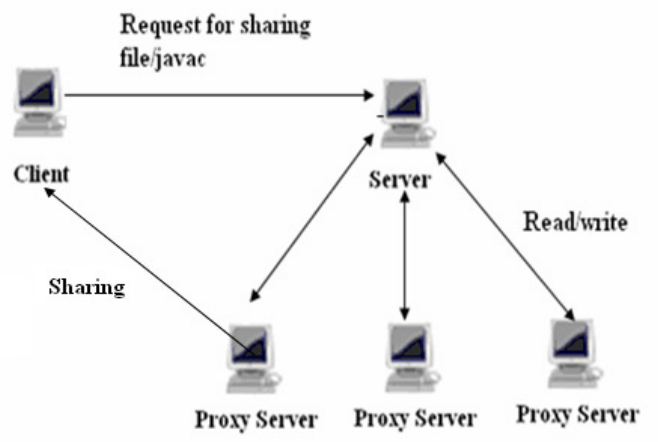

Figure 4. Cloud with Text Architecture 


\section{CONCLUSION}

Cloud solution embeds a state-of-the-art PIR protocol in a distributed environment, by utilizing a novel striping technique. Cloud can retrieve arbitrarily large blocks of information with a single query. We present a comprehensive solution that includes a data placement policy, result retrieval, and authentication mechanisms, which confirm the effectiveness and practicality of our scheme. Specifically, compared to the traditional client/server architecture, pCloud drops the query response time by orders of magnitude, and its performance improves linearly with the number of peers. Whether you call it Cloud Computing or utility computing, the omnipresent power of high-speed internet connections and linkages to databases, applications and processing power will change the way we work in communications. We may use Cloud Computing tools without being aware of what they actually are. We may learn our way into Cloud Computing applications that seem strange today. We will find entirely new applications in the Cloud to help send messages more effectively to target audiences. Young practitioners today will stand back and listen with wry smiles to their seniors who talk about the "good old days" when the PC first appeared and early Local Area Networks provided the first hint of productivity. In fact, they are smiling already at the old fogies.

\section{REFERENCES}

[1] Mancini,E.P.;Rak,M.;Villano,U.; Enabling Technologies: Infrastructures for Collaborative Enterprises, 2009. WETICE '09. 18th IEEE International Workshops on Digital Object Identifier: 10.1109/WETICE.2009.47 Publication Year: 2009,

[2] Foster,I.;YongZhao;Raicu,I.;Lu,S.; Text Computing Environments Workshop, 2008. GCE '08 Digital Object Identifier: 10.1109/GCE.2008.4738445 Publication Year: 2008

[3] Mancini, E.P.; Rak, M.; Villano, U.; Enabling Technologies: Infrastructures for Collaborative Enterprises, 2009. WETICE '09. 18th IEEE International Workshops on Digital Object Identifier:10.1109/WETICE.2009.47 Publication Year: 2009

[4] Vieira, K.; Schulter, A.; Westphall, C.B.; Westphall, C.M.; IT Professional Volume: 12 , Issue: 4 Digital Object Identifier: 10.1109/MITP.2009.89 Publication Year 2010;

[5] Shuai Zhang; Shufen Zhang; Xuebin Chen; Xiuzhen Huo; Future Networks, 2010. ICFN '10. Second International Conference on Digital Object Identifier: 10.1109/ICFN.2010.58 Publication Year: 2010

[6] AjayKumar, S.; Nachiappan, C.; Periyakaruppan, K.; Boominathan, P.; 2009 International Conference on Signal Processing Systems Digital Object Identifier: 10.1109/ICSPS.2009.106 Publication Year: 2009 


\section{AUTHORS}

Dr. S. Saravana Kumar received the Undergraduate Degree in Information Technology from Madras University, the Post Graduate degree in Computer Science and Engineering from Anna University , and Doctorate from Bharath university. He has published more than 45 publications in National and International journal proceeding. He has more than 11 years of teaching experience. His areas of interest includes Artificial Neural Networks, Image Processing, Data Mining, Data Structures, Database Management Systems, Distributed systems and Operating systems.

J.Lakshmi Priya is a third year student pursuing her B. tech Information Technology, Panimalar institute of Technology. She has attended several conferences and National level Symposium. She has submitted papers on cloud computing, peer to peer systems and search engine optimisation. Her domain of interest are Database management and systems, mobile optimization.

P. Hannah Jennifer is a third year student pursuing her B.Tech Information Technology, Panimalar Institute of technology. She has attended several conferences and National level symposium. She has submitted papers on peer to peer systems and search engine optimization. Her domain of Interest in area of Adhoc, ANN, Security in Sensor Network, Mobile Database and Data Mining.

N. Jeff Monica is a third year student pursuing her B.Tech Information Technology, Panimalar institute of technology. She has attended several conferences and National level symposium. She has submitted papers on system search engine optimization. Her domain of Interest are Database management and systems, web technology and web designing technology.

Z. Fathima is a third year student pursuing her B.Tech Information Technology, Panimalar Institute of Technology. She has attended several Conferences and National Level symposium. She has submitted papers on Cloud computing, peer to peer system and search engine optimization. Her domain of Interest are web technology, web designing, search engine optimisation.
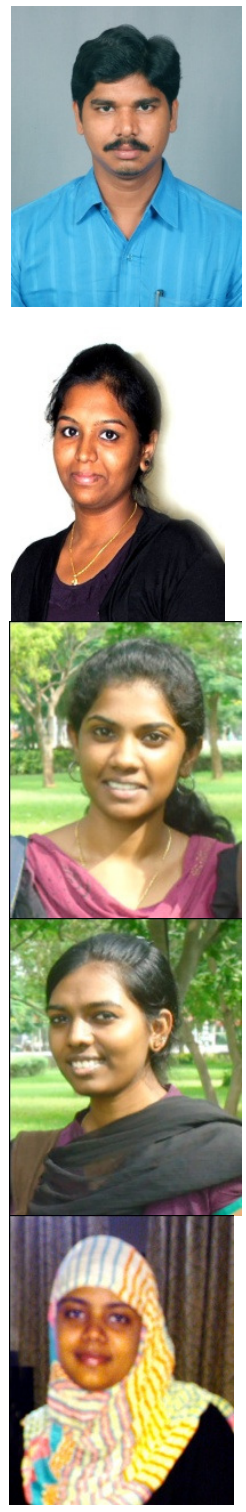